\title{
Finite Element Analysis of a Transtibial prosthetic during Gait Cycle
}

\author{
Faiz M. Rohjoni ${ }^{1}$, Mohd Nor Azmi Ab Patar ${ }^{1,3 *}$, Jamaluddin Mahmud ${ }^{1}$, Hokyoo Lee $^{2}$, Akihiko Hanafusa ${ }^{3}$ \\ ${ }^{1}$ Faculty of Mechanical Engineering, Universiti Teknologi MARA, Shah Alam, Selangor, Malaysia \\ ${ }^{2}$ Department of Mechanical and Control Engineering, Niigata Institute of Technology, Japan \\ ${ }^{3}$ Department of Bio-science and Engineering, Shibaura Institute of Technology, Japan \\ Email: *azmipatar@uitm.edu.my
}

\begin{abstract}
Prosthesis is an artificial part used by amputees as an alternative device to support activities of daily life. It is used to replace the amputated limb and mimic the human movement and locomotion. This paper aims to analyze the stress distribution of a transtibial prosthetic leg during gait cycle using CATIA V5. The dimension of the prototype was based on an average dimension of an actual human foot of Malaysian. The prototype implemented the integration of mechanical and electrical components. Furthermore, the movement of the prototype are based on deviations of angle between pylon and foot. The deviations were detected by rotary angle sensor which then triggered the DC motor to operate. Static analysis had been done using Generative Structural Analysis workbench in CATIA V5 software. Peak von Mises stress were found on the foot at toe off. The highest von Mises stress at the pylon beam was $995 \mathrm{MPa}$ and has stress of 156MPa on top of the pylon during heel strike. Furthermore, the foot has peak stress up to 3.18MPa. The result presented here may facilitate improvement of costeffective prosthetic leg.
\end{abstract}

Index Terms - active prosthetic leg, static simulation; transtibial prosthetic leg, prosthetic model, 3D prosthetic

\section{INTRODUCTION}

Prosthesis is an artificial component used to replace the missing limb that caused by injury or accident. The development of the prosthesis has started long way before the Dark Ages. During that time, most of the patient who lost their limb wanted to feel whole and complete again so that they can make their daily routine as usually. The growth of inventors of the prosthetic leg are enhanced by the World War I and World War II. During that time, there are many injuries sustained and the number of amputees is increasing rapidly. It opens the opportunities for experimentation and development of new type of prosthesis that can give more advantages to the user [1]. Numerous societies and organizations were formed to support the prosthetist and their innovation.

Prosthesis help the amputees to feel normal. After losing their limb, their daily routines change entirely. The amputee pace is slower and the stability is lesser compared to the non-amputee [2]. It makes it harder for them to move freely and they need to rely on wheelchair or walking stick to help them move from one place to another. There is a desire to feel whole and complete again. It is important that prosthesis satisfy this need as the advancement of the technology are moving rapidly from time to time. Samuel [3] proposed that active prosthetic leg can provide more natural gait rather a conventional passive prosthesis. The bionic prosthetic leg developed have flourish all over the world as a device that can mimic perfectly almost the human gait cycle. This is because human movement is complicated behavior involves the integration of nervous system that will result in motor action [4]. Active prosthetic leg can help a person to walk at better metabolic rate and energy consumption compared to the passive prosthetic leg as proposed by Herr [5]. It is supported by Margaret [6] who proposed that patient who use passive prosthetic leg will have their normal gait impaired which result in various risk such as risk of falling down and physiological pathologies. Moreover, Eilenberg [7] also found that normal and fast walking speed require more external energy and passive prosthetic leg cannot be used for this intention as it will only be a good approximation of ankle's function only during slow walking. The users wearing the conventional prosthesis will also walk slower as they need more metabolic energy as proposed by Eilenberg [8]. Although the growth of the better prosthetic legs is increasing, it is an expensive and many people cannot afford the technology $[9,10,11]$. To address the issue, many developers have designed the prosthetic devices that can be fabricated locally at low cost.

This paper presents to analyze the stress distribution of a transtibial prosthetic leg during gait cycle. There are two types of simulation that have been done to the prototype. The first one is finite element analysis for static simulation. Then, the other simulation is DMU Kinematic simulation using the same software, CATIA V5. This simulation advantage to determine the theoretical speed and acceleration of the prototype during the gait cycle $[12,13,14]$ after completed assembled. The properties and the specification of the prototype has been developed to be similar as the previous literature with added value of cost-effective material $[15,16]$. Then, the results obtained have been compared to the selected journal which related to the scope of preliminary studies. 


\section{Methodology}

\section{A. Design Methodology}

The scope of the preliminary studies focused on the development of an innovative mechanism for transtibial prosthesis and simulated the mechanical behavior using CATIA V5 software. In finite element analysis (FEA), the prosthetic socket was not included due to the complexity of the design. This study has been divided into different phases as illustrated in Fig. 1. For geometries configuration of the foot, it was made by the improvement of the previous study using reverse engineering techniques. The prototype dimension based on the average dimension of an actual human foot of Malaysian. The material used for the simulation was Polylactic Acid (PLA) plastic. The material characteristic revealed in Table III. After the FEA analysis was accomplished and the result was obtained. Then, the fabrication of the prototype was visualized using 3D printer where the filament consuming the same material as the simulation conducted. All the components that has been printed were assembled and integrated with electrical components. Then, the functionality of the system tested manually for its modification.

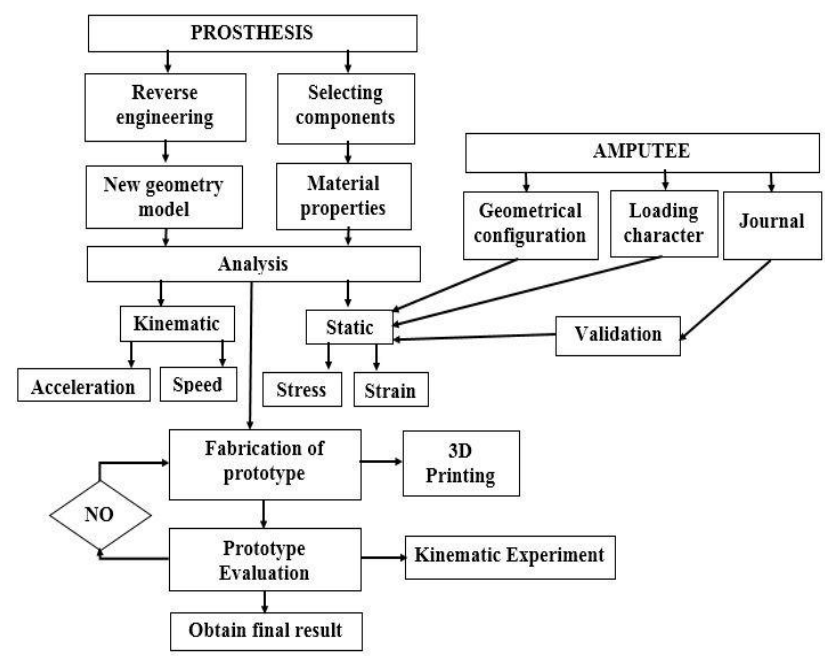

Figure 1. Flow chart for the modification method of active transtibial prosthetic leg

\section{B. Geometries}

The prosthetic leg has been developed into three segment including foot, pylon and ankle. The specifications of each segments are exposed in Table I. All of the segments are connected to each other using shaft and screws. The lower leg and foot are connected together through shaft whereas the ankle is connected to the foot using screws. Fig. 2 demonstrates the prototype model that has been modelled in CATIA V5. The 3D CAD software also be used for modeling mechanical parts. The vertical load and clamp location have been selected at the crucial parts for static simulation while the kinematic simulation has been composed with motions equations for speed and acceleration. The $3 \mathrm{D}$ model has been developed are represented by rigid body shape to replicate the human leg and foot. The initial position of the rigid body has been set and connected to each other by shaft and screws. The foot has been connected to the pylon using shaft and acted as fulcrum point for the pylon to move forward and backward.

Meanwhile, the ankle and the foot were connected together using screws. Each connector for parts sets as revolute axis to simulate the movements needed. The kinematic data was tracked using joints sensor during gait cycle.

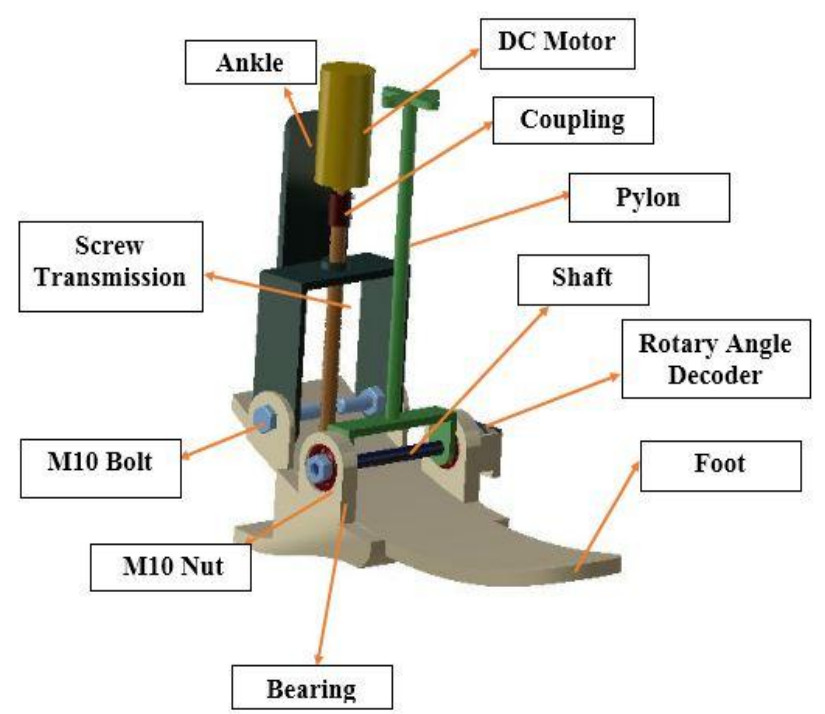

Figure 2. Completed assembled parts of transtibial prosthetic leg in CATIA V5

\section{Design Specification}

Table I shows the dimensions of the component that has been fabricated using in house low-cost 3D printer (Creality Ender 3 Pro). The dimensions selected are based on literature review and has been modified to fit the specification of the $3 \mathrm{D}$ printer.

TABLE I. MODEL SPECIFICATION

\begin{tabular}{|c|c|c|}
\hline \multirow{2}{*}{ Components } & Parameters & Dimensions (mm) \\
\hline \multirow{3}{*}{ Foot } & Length & 300 \\
\cline { 2 - 3 } & Width & 128 \\
\cline { 2 - 3 } & Thickness & 10 \\
\hline \multirow{3}{*}{ Pylon } & Height & 235 \\
\cline { 2 - 3 } & Width & 100 \\
\cline { 2 - 3 } & Diameter & 10 \\
\hline \multirow{3}{*}{ Ankle } & Length & 200 \\
\cline { 2 - 3 } & Width & 100 \\
\cline { 2 - 3 } & Thickness & 10 \\
\hline
\end{tabular}

The cost-effective transtibial prosthetic leg based on the best available design has been selected as a benchmark and the specification of the components has been recorded. The proposed components as listed in Table II has similar specification of established an active transtibial prosthetic leg nevertheless cheaper and easy to obtain in local market. 
TABLE II. COMPONENT SPECIFICATION

\begin{tabular}{|c|c|}
\hline Components & Suggested \\
\hline DC motor & RC DC Motor \\
\hline Transmission & Lead screw \\
\hline Controller & Arduino Uno \\
\hline Battery & Lithium polymer (LiPo) \\
\hline Bearing & Rolling bearing \\
\hline Sensor & Rotary angle sensor \\
\hline
\end{tabular}

Aforementioned, the main parts of transtibial prosthetic leg has been fabricated using Creality Ender 3 Pro V Slot semi assembled 3D Printer. It provided a good finishing Poly-lactic Acid (PLA) plastic-based 3D model using Fused Deposition Modeling (FDM) printing technique. Hence, PLA has a good compatibility with the 3D printer, therefore the material has been used to print the 3D model. Table III shows the properties of the PLA material.

TABLE III. PROPERTIES OF PLA MATERIAL

\begin{tabular}{|c|c|}
\hline Material & Polylactic Acid (PLA) Plastic \\
\hline Young's Modulus & $2004 \mathrm{MPa}$ \\
\hline Poisson's Ratio & 0.38 \\
\hline Density & $1200 \mathrm{~kg} / \mathrm{m}^{3}$ \\
\hline $\begin{array}{c}\text { Coefficient of thermal } \\
\text { expansion }\end{array}$ & $6.64 \times 10^{-5} / \mathrm{K}$ \\
\hline Yield Strength & $37 \mathrm{MPa}$ \\
\hline
\end{tabular}

\section{Numerical Analysis}

The parameter input for static simulation was obtained from Upunder [10]. The set of data are essential for measuring the vertical load applied when the model is used. The model has couple of input including the clamp where the position of the model is fixed and also vertical load distribution. The analysis assumes the average weight of a targeted amputee is $60 \mathrm{~kg}$. Then, converted into load in the Newton as in equation (1).

$$
F=\frac{m a}{2}
$$

The mass, $m$ is $60 \mathrm{~kg}$ and gravitational acceleration, $a$ is $-9.81 \mathrm{~m} / \mathrm{s}^{2}$. The axial load, $F$ estimated around $588 \mathrm{~N}$. After that, the axial load divided into two as this analysis only use one foot. The axial load applied in this analysis approximately $300 \mathrm{~N}$. The output parameter obtained the von Misses Stress and also the deformation of the model. During the initial stages of this analysis, the clamp position has been considered to gain the stress and deformation values during static simulation. The clamp position has been verified several times on different locations to obtain the accurate results. The clamp then has been applied in two phase which was the first phase at the proximal end of the pylon and second phase was the upper surface area of the pylon that connected to the socket. Then, axial load has been applied to the pylon on the bottom part of the pylon that has through hole for shaft that connected pylon to the foot. The axial load applied in vertical direction which represented the reaction force from the ground during stance phase. Fig. 3 illustrates the boundary condition applied to the pylon during static simulation. The clamp position has been fixed on the top part of the pylon where connected the pylon to the socket. The axial load applied on the bottom of the pylon as exposed in Fig. 3. The axial load applied from the bottom part of the pylon as it represents the Ground Reaction Force (GRF) during stance phase. However, this analysis does not include the prosthetic socket due to the complexity of the design. The load has four condition which are mid stance, heel strike, foot flat and toe off condition. The results obtained from the simulation has been compared with literature review for validation.

\section{RESULTS AND DISCUSSION}

During the first phase of FEA, the aim was to investigate the stress-strain behavior of the foot and also to find strain acting on the pylon. After simulation, the highest values of the total deformation of the foot was found during toe off phase as revealed in Fig. 4. The base of the foot can be seen shifted a little bit due to high force acting during toe off phase. Although the filament infill has been set to $100 \%$ and the foot base has been redesigned to have wider base up to $128 \mathrm{~mm}$, the highest translational displacement for the foot is during toe off which is $0.0128 \mathrm{~mm}$. Besides that, the peak equivalent stress of the toe and heel of the foot was during toe off phase. Table IV illustrates the von Mises value during stance phase. At heel strike, the stress was significant as toe off due to dorsiflexion angle of 30 degree. However, the heel and toe of the foot can withstand the axial load successfully as the stresses were low during foot flat and mid stance.

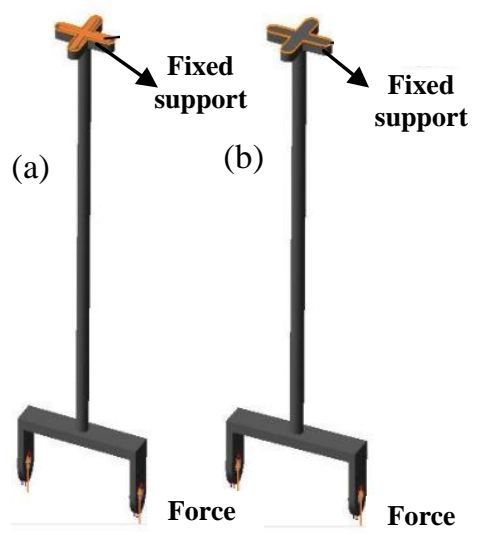

Figure 3. (a) Boundary condition during second phase of FEA at upper surface area of the pylon (b) Boundary condition applied during first phase of FEA at proximal end of top pylon 


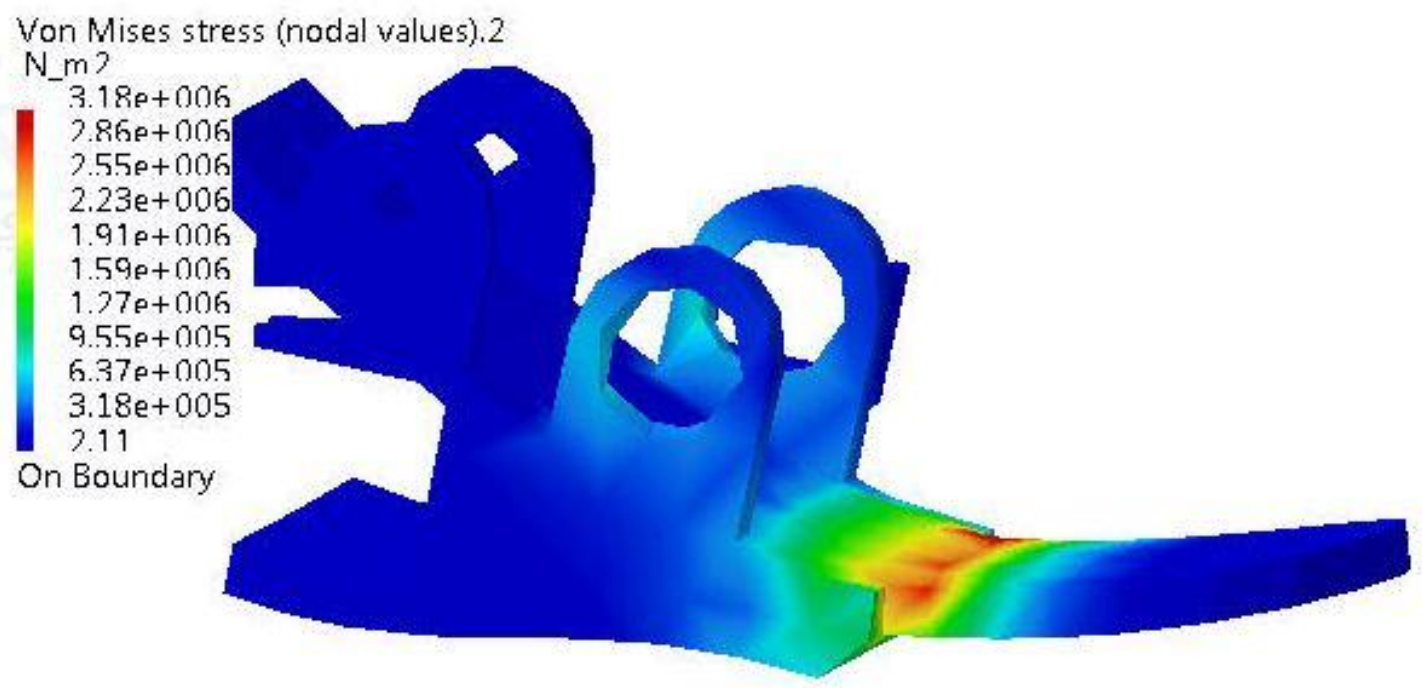

Figure 4. Deformation of foot at toe off condition

TABLE IV. Peak Von Mises StRess on the Heel and toe SPRing AT LOADing Condition

\begin{tabular}{|l|l|l|l|l|l|}
\hline Load condition & & Heel strike & Foot flat & Mid stance & Toe off \\
\hline Von Mises stress (MPa) & Toe & 0.00103 & $5.4 \times 10^{-7}$ & $1.08 \times 10^{-6}$ & 0.0099 \\
\hline & Heel & 0.00286 & 0.00107 & 0.00151 & 0.0523 \\
\hline
\end{tabular}

TABLE V. PeAK Von Mises Stress In SEVERAL Areas on the Pylon

\begin{tabular}{|c|c|c|c|c|c|c|}
\hline \multirow[t]{2}{*}{ Load Condition } & \multicolumn{6}{|c|}{$\begin{array}{c}\text { Peak von Mises stress in areas } \\
(\mathrm{MPa})\end{array}$} \\
\hline & 1 & 2 & 3 & 4 & 5 & 6 \\
\hline Mid Stance & 9.27 & 12 & 12 & 12 & 12 & 27.9 \\
\hline Heel strike & 742 & 538 & 423 & 263 & 214 & 114 \\
\hline Toe off & 359 & 295 & 225 & 157 & 995 & 591 \\
\hline Foot flat & 5.31 & 6 & 6 & 6 & 6.29 & 19.1 \\
\hline
\end{tabular}

Besides that, as shown in Table V, its summaries the value of peak von Mises stresses in different area on the pylon as illustrated in Fig. 6. Due to the bending load on the pylon during simulation, the pylon has slight deflection. The highest von Mises stress at the pylon during simulation is at heel strike. This is due to compressive load and dorsiflexion angle of 30 degrees. More-over, the components of this model are mostly stressed during toe off. Fig. 6 illustrates the view of von Mises stress distribution in the pylon that connect it to the pylon with the areas of peak stress areas marked. Table VI shows the values for the peak von Mises stress on top of the pylon in three different areas. Furthermore, small diameter of pylon increases the force due to small surface area. The diameter of the pylon is just $10 \mathrm{~mm}$; thus, the stress is high on the pylon. The value of von Mises stress tends to decrease throughout the peak area to illustrate that the prototype is need to modify to get better mechanism to withstand the load applied. The lower the von Mises stress the better the mechanism.

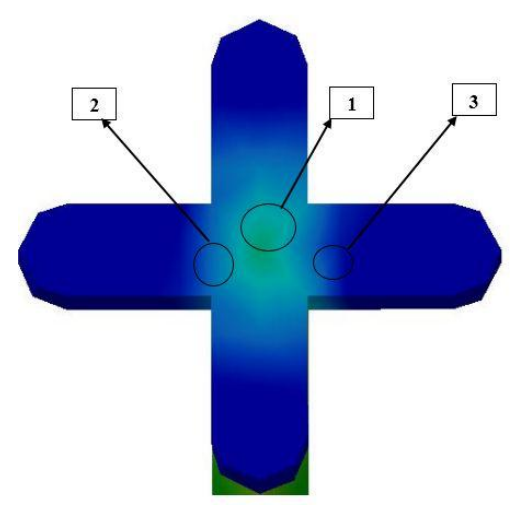

Figure 5. Area of peak von Mises stress on top of the pylon 


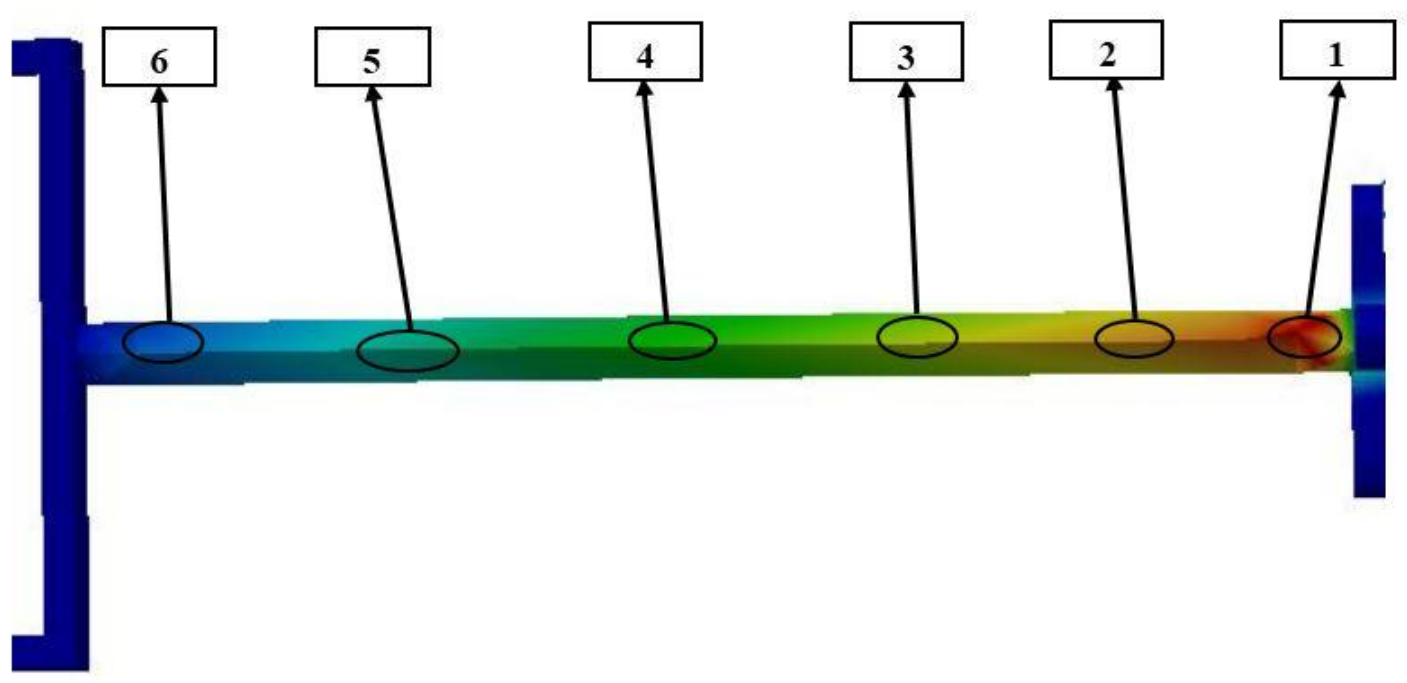

Figure 6. Areas of peak von Mises stress on the pylon

TABLE VI. PEAK Von Mises StRESS ON TOP OF THE PyLON

\begin{tabular}{|l|c|c|c|}
\hline \multirow{2}{*}{ Load Condition } & \multicolumn{3}{|c|}{ Peak von Mises stress in areas } \\
& $\mathbf{2}$ & $\mathbf{2}$ & $\mathbf{3}$ \\
\cline { 2 - 4 } & $\mathbf{1}$ & 2.88 & 2.59 \\
\hline Mid Stance & 4.91 & 44.3 & 57.2 \\
\hline Heel strike & 156 & 22.7 & 28.5 \\
\hline Toe off & 70.8 & 1.44 & 1.35 \\
\hline Foot flat & 2.48 & & \\
\hline
\end{tabular}

Fig. 5 demonstrates the stresses on top of the pylon. The top of the pylon was set as boundary condition on the proximal end of it and also the entire surface on the top. This boundary condition was set as it represents the connection between the pylon and the socket as the socket was not included in FEA. The highest von Mises stress was at heel strike. The peak von Mises stress was $156 \mathrm{MPa}$. It demonstrated that the top of the pylon needs better improvement in term of the mechanism and dimension. However, during mid stance, the top of the pylon has the smallest stress compared to another stance phase. The results illustrated that the pylon also has high von Mises stress at the top of the pylon at toe off. As mentioned before, foot of the model has peak stress also at toe off.

\section{RECOMMENDATIONS AND FUTURE WORKS}

The new model that has been developed was based on previous study. It was an improvement from the literature reviews. The prototype can be improved by increasing the diameter of the pylon. By increasing the diameter, it can improve the strength of the pylon and lower the von Mises stress through-out the pylon. Besides that, the ankle needs to be redesigned subsequently the DC motor can turn the screw transmission more smoothly and increase the percentage to actually mimic the gait cycle. The current ankle design of the model has small diameter and gave high friction to the lead screw. High friction will increase the rotational speed produced by the DC motor. Moreover, the lead screw can be flattened at one end. The flattened area can be connected to the DC motor using coupling and lower the friction with the ankle. Furthermore, the prototype should be printed using 3D printer using 80 to $100 \%$ of density infill. This will verify that the prototype has enough thickness. Thus, the test for its functionality can be conducted. DC motor need enough voltage in order to have the desired torque and power. Battery should be at least $12 \mathrm{~V}$ or use lithium polymer (LiPo) battery as secondary choice. This project can be studied further on the simulation works. In future, SimMechanics soft-ware will be used in kinematic simulation to analyze systems behavior as it will give better results. Furthermore, for static simulation, we should use better software to implement the Finite Element Analysis. ABAQUS or ANSYS software can be used for static simulation to obtain accurate data for further analysis. Thus, this research also needs better pylon mechanism to withstand the average weight of person. The modification will make our prototype more assurance in term of structural strength and more energy efficient in the cost effective an active transtibial prosthetic leg.

\section{CONCLUSIONS}

The results when the load applied in the four conditions are shown as table above. At heel strike 
condition, the pylon has several critical points where the Von Misses stress is high. This critical point where Von Misses stress is highest cause deformation on the pylon. The diameter of the pylon is just $1 \mathrm{~cm}$ or $10 \mathrm{~mm}$ only. That is why the deformation happen and the Von Misses stress is high. Although the top of the pylon at the connectors were deformed, but it has low Von Misses stress. The stress from the top of the pylon passes through the pylon itself to the bottom of pylon and that is where most of the compressive stress stored and cause the high Von Misses stress. It is critical to lower the stress to prevent the pylon to have bigger deformation. This project use Poly-lactic Acid (PLA) plastic as material and has properties as shown in Table III. The model needs to be redesign to have better results in FEA. The model needs to have better diameter at the pylon. Small diameter of pylon will cause high stress due to small surface area. By increasing the diameter of pylon, the model can have better results in FEA. The bottom part of the pylon that connect pylon to the foot also need to be bigger in term of its size. It will make sure that the pylon can have suitable and bigger part as its base. Although the value of stress on pylon is high, it will only cause deflection of $0.958 \mathrm{~mm}$. Other than that, this study has used 3D printer to fabricate the prototype. The prototype has only $30 \%$ of density infill. The part that has been printed by using the printer is ankle, foot and pylon. The prototype needs to be printed from $80-100 \%$ of density infill so that it will have greater strength and thickness to be used as prosthetic leg. The printer has not enough space to print all the component on 1:1 scale. Two parts have been compromised in term of the size. The foot and pylon have been scaled down a little

\section{CONFLICT OF INTEREST}

The authors declare no conflict of interest.

\section{AUTHOR CONTRIBUTIONS}

Mohd Nor Azmi Ab Patar and Faiz M. Rohjoni, conceived of the presented idea. Jamaluddin Mahmud developed the theoretical framework and Faiz M. Rohjoni performed the numerical simulations. Hokyoo Lee contributed to the interpretation of the results and Akihiko Hanafusa verified the analytical methods. Mohd Nor Azmi Ab Patar encouraged Faiz M. Rohjoni to investigate finite element analysis of a transtibial prosthetic during gait cycle and supervised the findings of this work. All authors discussed the results and contributed to the final manuscript.

\section{ACKNOWLEDGMENT}

This research was supported by rehabilitation research group. We are thankful to our colleagues who provided expertise that greatly assisted the research. We are also grateful to Munir Safian for assistance with designing and programming electrical circuit. We are also immensely grateful to FYP2 panels for their comments on an earlier version of the manuscript, although any errors are our own and should not tarnish the reputations of these esteemed professionals. All authors declare that they have no conflicts of interest.

\section{REFERENCES}

[1] K. Englehart, B. Hudgins, P. A. Parker, "Analysis of a Lower Limb Prosthesis," IEEE Transactions on Biomedical Engineering, vol. 48, no. 3, pp. 302-311, 2001.

[2] R. D. Gregg, T. Lenzi, L. J. Hargrove, J. W. Sensinger, "Virtual constraint control of a powered prosthetic leg: From simulation to experiments with transfemoral amputees," IEEE Transactions on Robotics, vol. 30, no. 6, pp. 1455-471., 2014.

[3] Z. O. Abu-Faraj, G. F. Harris, P. A. Smith, S. Hassani, "Human gait and Clinical Movement Analysis," Wiley Encyclopedia of Electrical and Electronics Engineering, 2015.

[4] H. M. Herr, S. K. Au, "The importance of series and parallel motor elasticity," IEEE Robotic \& Automation Magazine, 2008.

[5] M. Islam, A. Haque, (2012). Design and development of an EMG driven microcontroller based prosthetic leg. BangladeshJournal, 4(1). [Online]. Available: https://doi.org/10.3329/bjmp.v4i1.14695

[6] M. Johnstone, Illustrated by Estrid Barton, "Restoration of motor function in the stroke patient: A physiotherapist's approach". Published: Edinburgh; New York; Livingstone, 1987 3rd ed.

[7] M. F. Eilenberg, H. Geyer, H. Herr, "Control of a powered anklefoot prosthesis based on a neuromuscular model," in IEEE Transactions on Neural System and Rehabilitation Engineering, vol. 18, pp. 164-173, 2010.

[8] M. F. Eilenberg, J. Y. Kuan, H. Herr, "Development and evaluation of a powered artificial gastrocnemius for transtibial amputee gait," Journal of Robotics, 2018.

[9] S. K. Au, H. Herr, "Initial experimental study on dynamic interaction between an amputee and a powered ankle-foot prostheses," in Workshop on Dynamic Walking: Mechanics and Control of Human and Robot Locomotion, Ann Arbor, May 2006

[10] V. Upender, E. Srikanth, G. Karthik, N. Kumar, "Design modeling and optimization of a prosthetic runner blade," vol. 3, pp. 64-70.

[11] D. A. Winter, Biomechanics and Motor Control of Fourth Edition, 2009.

[12] S. A. Abdelwahab, "Modeling and simulation of lower limb dynamics using simmechanics for potential applications in bilateral prosthesis control," May 2017.

[13] M. Omasta and D. Palou, "Medical engineering \& physics finite element analysis for the evaluation of the structural behaviour, of a prosthesis for trans-tibial amputees," vol. 34, pp. 38-45, 2012.

[14] A. B. Patar MNAB, T. Komeda, J. Mahmud, "Force assisted hand and finger device for rehabilitation," In: 2014 International Symposium on Technology Management and Emerging Technologies. Bandung; 2014.p. 133-8. https://doi:10.1109/ISTMET.2014.6936493.

[15] B. A. Patar, M. N. Azmi, H. Ramli, J. Mahmud, A. H. Yusof, "Efficacy and safety testing of a new biologically based design ankle foot orthosis in healthy volunteer," Applied Mechanics and Materials, vol. 110, pp. 1953-1957, 2012.

[16] M. N. A. A. Patar, T. Komeda, L. C. Yee, and M. Jamaluddin, "Model-Based Systems Engineering of a Rehabilitation Device," Jurnal Teknologi, vol. 76, no. 4, pp. 101-106, 2015.

Copyright (C) 2020 by the authors. This is an open access article distributed under the Creative Commons Attribution License (CC BYNC-ND 4.0), which permits use, distribution and reproduction in any medium, provided that the article is properly cited, the use is noncommercial and no modifications or adaptations are made.

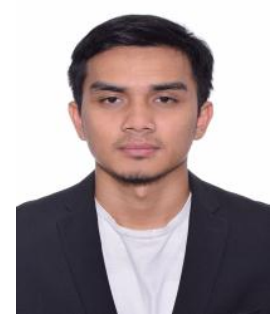

Faiz M. Rohjoni born at Johor Bahru on 8th July 1995. He received a Bachelor Degree in Mechanical Engineering from Universiti Teknologi MARA (UiTM) Shah Alam on July 2019. His research interests include prosthetic leg and finite element analysis (FEA). 


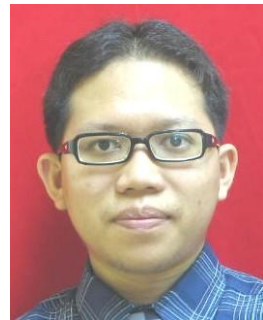

Mohd Nor Azmi Ab. Patar has a Ph.D degree in (Biomechatronic) Engineering, an MSc (Mechanical) Engineering degree and a B.Eng. (Hons.) Mechanical Engineering degree from Shibaura Institute of Technology Japan. He joined the Faculty of Mechanical Engineering UiTM as a lecturer in 2009 and currently as a Senior Lecturer. Prior to that, he has worked about one year as an instrument engineer at Rohm Wako Electronic (M) Sdn. Bhd. His research interests include biomechatronic, mobile robots, assistive technology, rehabilitation engineering, personal mobility, prosthetic \& orthosis, exoskeleton, Artificial Intelligence and Robotics.

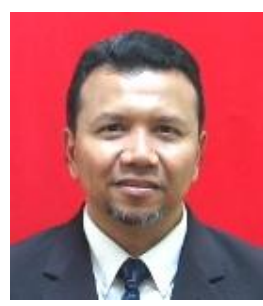

Jamaluddin Mahmud has a $\mathrm{PhD}$ degree in (Biomechanical) Engineering from Cardiff University UK, an MSc (Manufacturing) Engineering degree from International Islamic University, Malaysia (IIUM) and a B.Eng. (Hons.) Mechanical Engineering degree from Universiti Teknologi MARA (UiTM). He joined the Faculty of Mechanical Engineering UiTM as a lecturer in 2001. Prior to that, he has worked about three as a service engineer at UMW Equipment Sdn. Bhd. Furthermore, due to his expertise and experience, he sits in many committees, editorial boards, training groups and evaluating teams in various events at national and international level.

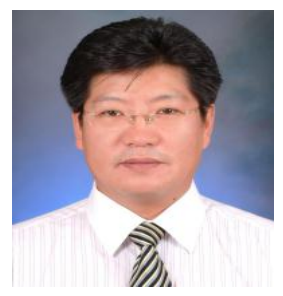

Hokyoo Lee received his Dr. Eng. degree in 2006 from Shibaura Institute of Technology Graduate School of Engineering, Japan and became an assistant professor faculty of life design Toyo University. In 2010, he was a researcher at Hyogo Prefectural the Hyogo Institute of Assistive Technology, Japan. He now works as an associate professor, Faculty of Engineering, Niigata Institute of Technology.

His current research interests include mechatronics, robotics, rehabilitation engineering and welfare engineering.

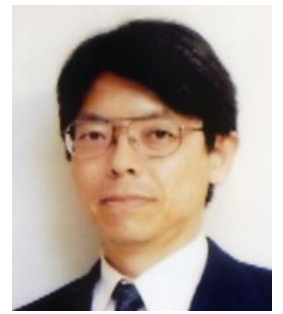

Akihiko Hanafusa received a $\mathrm{PhD}$ and master's and bachelor's degree in engineering from the University of Tokyo. He became a lecturer and associate professor at Polytechnic University in 1993. He has been working as a full-time professor at SIT since 2009. His interests lie in the fields of human welfare, life support and biomedical engineering. 